\title{
AGROGSTA
}

Journal Agroista. Vol. 5 ,No.2 November 2021

Journal home page: https://jurnal.instiperjogja.ac.id/index.php/AGI

ISSN : $2597-3835$

e-ISSN : : $2684-7019$

\section{RESPON PERTUMBUHAN PUERARIA JAVANICA TERHADAP DOSIS RHIZOBIUM SP. PADA BEBERAPA JENIS TANAH YANG BERBEDA}

\section{PUERARIA JAVANICA GROWTH RESPONSE TO RHIZOBIUM SP. DOSAGES IN SEVERAL DIFFERENT SOIL TYPES}

\author{
Ari Selfandi ${ }^{1}$, Ryan Firmansyah ${ }^{1}$, Pauliz Budi Hastuti ${ }^{1}$ \\ ${ }^{1}$ Department of Agrotechnology, Faculty of Agriculture, Stiper Agricultural Institute, \\ Yogyakarta, Indonesia \\ Email koresponensi: ryan@instiperjogja.ac.id
}

\begin{abstract}
This study aims to determine the growth response of Pueraria javanica to Rhizobium sp. doses on different soil types. This research was conducted in the local community garden located in Maguwoharjo Depok District, Sleman Regency, D. I. Yogyakarta at an altitude of 118 Meters Above sea level. The research method used is factorial with a complete randomized design (RAL). The first factor is the dose of Rhizobium sp. sp. consists of 4 levels, namely $0 \mathrm{~g}$ (control), $5 \mathrm{~g}, 10 \mathrm{~g}$, and $15 \mathrm{~g}$. The second factor is the type of soil consisting of 3 levels, namely regosol, latosol, and grumosol. The results showed interaction between the dose of Rhizobium sp. with different types of soil against the best plant height in the soil type grumusol with various doses of Rhizobium sp. and the best dry root weight in the soil type grumusol with a dose of Rhizobium sp. $10 \mathrm{~g}$. Rhizobium sp. dose gives the same effect on the growth of Pueararia javanica in number of leaves, fresh weight of header, dry weight of header and number of root, except at fresh root weight.
\end{abstract}

Keywords : Pueraria javanica, Rhizobium sp., regosol, latosol, grumusol 


\section{PENDAHULUAN}

Konversi lahan perkebunan kelapa sawit yang diupayakan melalui berbagai cara salah satunya adalah penanaman leguminosae sebagai penutup tanah. Tanaman penutup tanah ini memiliki berbagai fungsi menekan pertumbuhan gulma, menghasilkan bahan organik dan mencegah erosi. Tanaman ini dapat memperbaiki struktur tanah serta memengaruhi kadar nitrogen pada tanah dengan adanya aktivitas fiksasi nitrogen dalam bintil akar. Salah satu jenis tanaman leguminosae adalah Pueraria javanica (Purba, 2005).

Pueraria javanica merupakan jenis tanaman leguminosae yang menjalar di perkebunan kelapa sawit sebagai tumbuhan perintis. Tanaman ini memiliki kemampuan dalam mengikat unsur nitrogen.

Simbiosis Rhizobium sp. dengan tanaman legum dicirikan oleh pembentukan bintil akar. Rhizobium sp. memiliki spesifitas tinggi dalam membentuk bintil akar. Bakteri ini hanya akan membentuk bintil akar pada akar yang sesuai dan mampu mengikat nitrogen di udara. Apabila bersimbiosis dengan tanaman legum, kelompok bakteri ini akan menginfeksi akar tanaman dan membentuk bintil akar (Harsanto dkk.,2012).

Media tanam yang baik adalah yang mampu menyediakan unsur hara, air dan oksigen yang cukup untuk proses metabolisme tanaman di dalam tanah. Tanah latosol mempunyai ciri morfologi yang umum ialah tekstur lempung sampai geluh, struktur remah sampai gumpal lemah dan konsistensi gembur. Warna tanah sekitar merah tergantung susunan mineralogi, bahan induk, drainase, umur tanah, dan keadaan iklim. Kemasaman tanah asam-agak asam, kejenuhan basa lebih dari 35\%, dan tingkat kesuburan rendah-medium (Harjowigeno et al., 2005).

Tanah regosol memiliki tekstur tanah biasa kasar, struktur remah, konsistensi lepas sampai gembur dan $\mathrm{pH}$ 6-7. Umumnya jenis tanah ini belum membentuk agregat sehingga peka terhadap erosi. Umumnya cukup mengandung unsur $\mathrm{P}$ dan $\mathrm{K}$ yang masih segar dan belum siap untuk diserap tanaman, tetapi kekurangan unsur $\mathrm{N}$.

Tanah grumusol merupakan tanah dengan kandungan liat yang tinggi yang dikaitkan dengan ruang pori aerasi sedikit dan permeabilitas yang sangat rendah.

Menurut Mulyadi (2012) pemberian dosis pada benih Pueraria javanica dengan dosis Rhizobium sp. $10 \mathrm{~g}$ pada tanah regosol benih dapat meningkatkan bobot kering bintil akar sedangkan pemberian $5 \mathrm{~g}$ benih menurunkan bobot kering bintil akar bila dibandingkan dengan kontrol. Dalam penelitian ini akan dicoba pengaplikasian dosis bakteri Rhizobium sp. dengan jenis tanah yang berbeda. 


\section{METODOLOGI}

Penelitian dilakukan dilahan dikebun masyarakat setempat yang terletak di Maguwoharjo Kecamatan Depok, Kabupaten Sleman, D.I. Yogyakarta pada ketinggian 118 Mdpl. Penelitian dilaksanakan pada bulan Maret sampai Mei 2020. Penelitian ini menggunakan metode percobaan dengan rancangan acak lengkap faktorial $4 \times 3$ masingmasing 5 ulangan tanaman tiap perlakuan. Faktor pertama adalah dosis Rhizobium sp. terdiri dari 4 aras, yaitu 0 kontrol, $5 \mathrm{~g}, 10 \mathrm{~g}, 15 \mathrm{~g}$. Faktor kedua adalah jenis tanah yang terdiri dari 3 aras yaitu regosol, latosol, grumosol. Jumlah tanaman yang dibutuhkan 12 kombinasi x 5 ulangan = 60 tanaman. Data dianalisis menggunakan sidik ragam (Anova) pada jenjang $5 \%$. Apabila terdapat beda nyata, dilakukan uji Duncan Multiple Range Test (DMRT) pada jenjang nyata $5 \%$.

Penyiapan media tanam, tanah yang diambil yaitu lapisan atas ( top soil ) yang subur dan gembur serta bebas dari hama penyakit. Kemudian tanah tersebut dimasukkan ke dalam polybag. Jarak antar polybag adalah $30 \mathrm{~cm}$. Penyiapan benih dimulai dengan mengambil benih Pueraria javanica (Pj) kemudian dicuci bersih dengan cara diangin-anginkan kurang lebih $2 \mathrm{~s} / \mathrm{d} 3$ hari hingga kulitnya tidak berlendir. Setelah itu, dilakukan pemilihan benih dengan kriteria benih bernas/berisi penuh, tidak kisut, tidak berwarna coklat, tidak busuk, serta bentuknya sempurna. Selanjutnya dipilih benih-benih yang seragam untuk dikecambahkan. Penanaman dilakukan setelah media tanam telah siap. Benih Pueraria javanica ditanam dalam media tanam yang telah disiapkan. Kemudian siapkan pemberian dosis Rhizobium sp. yang dilakukan sebelum benih ditanam. Pemberian Rhizobium sp. sesuai dengan perlakuan yaitu : 0, 5, 10, dan $15 \mathrm{~g}$. Kemudian pemeliharaan meliputi Penyiraman dilakukan setiap hari, satu kali sehari pada sore hari hingga mencapai kapasitas lapangan. Pengendalian gulma yang tumbuh di polybag disiang secara manual, dilakukan setiap ada gulma yang tumbuh pada tanaman, hal ini dilakukan agar tidak terjadi persaingan dalam penyerapan unsur hara dan air. Pemupukan dilakukan perlakuan kontrol dicampur dengan Bahan organik yang digunakan adalah pupuk hijau dari Mucuna bracteata yang diletakan dipermukaaan tanah regosol,grumusol dan latosol 


\section{HASIL DAN PEMBAHASAN}

Hasil analisis yang disajikan Tabel 1 dan Tabel 2 menunjukkan bahwa ada interaksi nyata antara dosis Rhizobium sp. dengan jenis tanah yang berbeda pada parameter tinggi tanaman dan berat kering akar.

Tabel 1. Interaksi dosis Rhizobium sp. dan jenis tanah yang berbeda terhadap tinggi tanaman Pueraria javanica

\begin{tabular}{|c|c|c|c|c|}
\hline $\begin{array}{l}\text { Dosis } \\
\text { Rhizobium sp. } \\
\text { (g) }\end{array}$ & $\begin{array}{l}\text { Jenis Tana } \\
\text { Regosol }\end{array}$ & Latosol & Grumusol & Rerata \\
\hline 0 & $185,00 \mathrm{c}$ & $234,20 \mathrm{a}$ & $242,40 \mathrm{a}$ & 220,53 \\
\hline 5 & $223,00 a b$ & $234,20 \mathrm{a}$ & $235,40 \mathrm{a}$ & 230,60 \\
\hline 10 & $238,20 \mathrm{a}$ & $226,40 a b$ & $240,60 \mathrm{a}$ & 235,06 \\
\hline 15 & $205,00 \mathrm{bc}$ & $234,20 \mathrm{a}$ & $237,60 \mathrm{a}$ & 225,60 \\
\hline Rerata & 212,80 & 232,25 & 239,00 & $(+)$ \\
\hline
\end{tabular}

Keterangan : Angka rerata yang diikuti huruf yang sama pada kolom atau baris yang sama menunjukkan tidak berbeda nyata berdasarkan uji DMRT pada jenjang nyata $5 \%$.

Tabel 2. Interaksi dosis Rhizobium sp. dan jenis tanah yang berbeda terhadap berat kering akar Pueraria javanica

\begin{tabular}{|c|c|c|c|c|}
\hline \multirow{2}{*}{$\begin{array}{c}\text { Dosis } \\
\text { Rhizobium sp. (g) }\end{array}$} & \multicolumn{3}{|c|}{ Jenis Tanah } & \multirow{2}{*}{ Rerata } \\
\hline & Regosol & Latosol & Grumusol & \\
\hline 0 & $0,26 \mathrm{bc}$ & $0,22 \mathrm{bc}$ & $0,54 a b$ & 0,66 \\
\hline 5 & $0,28 \mathrm{bc}$ & 0,32 & $0,54 a b$ & 0,78 \\
\hline 10 & $0,26 \mathrm{bc}$ & $0,20 \mathrm{bc}$ & $0,62 \mathrm{a}$ & 0,66 \\
\hline 15 & $0,54 a b$ & $0,16 \mathrm{c}$ & $0,20 \mathrm{bc}$ & 0,76 \\
\hline Rerata & 0,93 & 0,78 & 1,75 & $(+)$ \\
\hline
\end{tabular}

Keterangan: Angka rerata yang diikuti huruf yang sama pada kolom atau baris yang sama menunjukkan tidak berbeda nyata berdasarkan uji DMRT pada jenjang nyata $5 \%$ 
Tabel 1 dan Tabel 2 menunjukkan bahwa pemberian dosis Rhizobium sp. berpengaruh nyata terhadap parameter tinggi tanaman dan berat kering akar. Kombinasi yang paling baik terdapat pada jenis tanah grumusol dengan berbagai dosis Rhizobium $s p$. dan tidak berbeda nyata pada latosol. Hal ini diduga karena grumusol merupakan tanah yang didominasi oleh fraksi lempung dengan kandungan lebih dari 40\%, fraksi lempung memiliki ukuran koloid yang rendah sehingga memiliki luas permukaan jenis yang besar, sehingga memiliki kemampuan menyerap dan menyimpan air yang tinggi, membantu membentuk agregat dan menyediakan hara,kapasitas yang baik dan melepaskan air lambat. Hal ini sesuai dengan yang disampaikan Harsanto (2012) bahwa penggunaan lempung dapat memperbaiki struktur dan pori mikro. Pada tanah latosol Tanah ini didominasi oleh lempung kaolinite sehingga drainasenya tidak terlalu buruk. Kandungan unsur hara dalam tanah latosol relatif rendah, kapasitas tukar kation rendah, dan jumlah basa-basa rendah. Selain itu derajat kemasaman $(\mathrm{pH})$ tanah rendah, kandungan silica dan sesquioksida rendah, serta al-dd dan Fe-dd tinggi. Tanah latosol mengandung bahan organik dan nitrogen yang tergolong cukup tinggi (Damanik,2010).Tinggi tanaman yang terendah pada tanah regosol karena tanah regosol memiliki kelemahan KPK (kapasitas pertukaran kation) yang rendah, kandungan bahan organik rendah, konsistensi lepas sampai gembur, kapasitas menahan air rendah (Damanik,2010)

Tabel 3. Pengaruh pemberian dosis Rhizobium sp. terhadap pertumbuhan benih Pueraria javanica

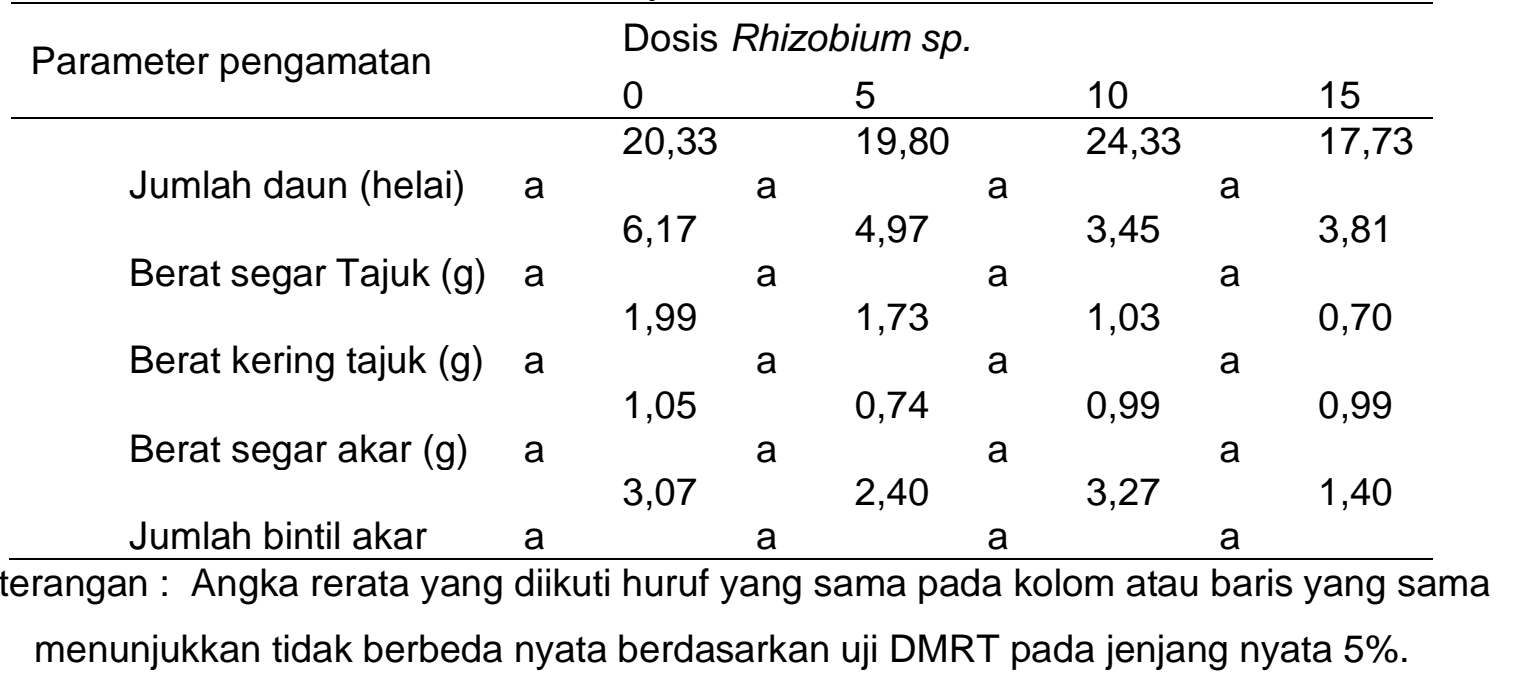

Hasil analisis Tabel 3 menunjukkan bahwa pemberian tanpa Rhizobium sp. (0 g/tanaman) dan Rhizobium sp. pada berbagai dosis menghasilkan pertumbuhan tanaman Pueraria javanica pada parameter jumlah daun, berat segar tajuk, berat kering tajuk, berat segar akar dan jumlah bintil akar yang tidak berbeda nyata. Hal ini diduga karena sudah ada Rhizobium sp. endogen yang ada didalam tanah dan kemungkinan tanah yang digunakan sudah pernah ditanami oleh tanaman leguminosae. Kemampuan Rhizobium sp. mengikat unsur hara nitrogen yang sangat dibutuhkan tanaman Pueraria javanica untuk 
mengoptimalkan pertumbuhanya. Hal ini juga yang disampaikan oleh Kurniaty dkk (2013) dalam penelitiannya menyebutkan bahwa inokulasi Rhizobium sp. secara nyata mampu memacu pertambahan tinggi tanaman sehingga tidak perlu diberikan lagi unsur hara nitrogen dari pupuk.

Tabel 4. Pengaruh pemberian jenis tanah yang berbeda terhadap pertumbuhan benih Pueraria javanica

\begin{tabular}{|c|c|c|c|c|c|c|c|}
\hline \multirow{2}{*}{$\begin{array}{l}\text { Parameter } \\
\text { pengamatan }\end{array}$} & \multicolumn{7}{|c|}{ Jenis Tanah } \\
\hline & \multicolumn{3}{|c|}{ Regosol } & \multicolumn{2}{|c|}{$\frac{\text { Latosol }}{1865}$} & \multicolumn{2}{|c|}{ Grumusol } \\
\hline Jumlah daun (helai) & 22,35 & $\mathrm{p}$ & $p$ & 18,65 & & 20,65 & $\mathrm{p}$ \\
\hline Berat segar Tajuk (g) & 5,75 & $\mathrm{p}$ & & 4,65 & $p$ & 3,39 & $p$ \\
\hline Berat kering tajuk (g) & 1,37 & $p$ & & 0,85 & $\mathrm{p}$ & 1,86 & $p$ \\
\hline Berat segar akar $(\mathrm{g})$ & 1,17 & $p$ & & 0,79 & $q$ & 0,63 & $q$ \\
\hline Jumlah bintil akar & 2,10 & $p$ & & 3,20 & $p$ & 2,30 & $p$ \\
\hline
\end{tabular}

Keterangan : Angka rerata yang diikuti huruf yang sama pada kolom atau baris yang sama menunjukkan tidak berbeda nyata berdasarkan uji DMRT pada jenjang nyata $5 \%$.

Pada perlakuan jenis tanah yang berbeda (tanah regosol, latosol, dan grumusol) tidak ada pengaruh nyata terhadap parameter jumlah daun, berat segar tajuk, berat kering tajuk, dan jumlah bintil akar. Hal ini diduga karena didalam ketiga jenis tanah ini memberikan unsur hara atau nutrisi yang sama baik untuk pertumbuhan tanaman. Diketahui bahwa jika unsur hara seperti $P$ diberikan ke dalam tanah maka akan terjadi proses kesetimbangan antara larutan dan kompleks padatan, bentuk kesetimbangan itu bisa berupa fiksasi ataupun pelarutan unsur lainnya. Menurut Ige dkk (2005) bahwa sifat tanah seperti kandungan Al dan kadar lempung berpengaruh nyata terhadap kapasitas fiksasi $\mathrm{P}$ oleh tanah. Hal ini diduga karena aerasi tanah erat kaitannya dengan kadar oksigen didalam tanah. Tanah yang aerasinya baik memungkinkan masuknya udara dalam tanah, sehingga akan mengandung oksigen yang cukup pula (Anonim, 2018). Hal tersebut menunjukkan bahwa tanah dengan aerasi baik menghasilkan LPT ( laju pertumbuhan tanaman) lebih tinggi dibandingkan tanah dengan aerasi buruk, karena aerasi buruk dapat mengganggu pertumbuhan tanaman dan akar, bahkan juga menekan kemampuan absorbsi air dan mengurangi permeabilitas akar terhadap air. Hal itu sejalan dengan yang disampaikan Gardner dkk (1991) air sangat dibutuhkan oleh tanaman karena merupakan komponen utama dalam sel-sel untuk menyusun jaringan tanaman khususnya juga untuk pertumbuhan klorofil sehingga pertumbuhan daun akan optimal dengan memiliki jumlah daun dan luas daun yang besar maka akan meningkatkan nilai LAB ( laju asimilasi bersih ) dan LPT ( laju pertumbuhan tanaman). 


\section{KESIMPULAN}

Terjadi interaksi antara dosis Rhizobium sp. dengan berbagai jenis tanah terhadap tinggi tanaman terbaik pada jenis tanah grumusol dengan berbagai dosis Rhizobium sp. dan pada berat kering akar terbaik pada jenis tanah grumusol dengan dosis Rhizobium sp. $10 \mathrm{~g}$. Dosis Rhizobium sp. memberikan pengaruh yang sama terhadap pertumbuhan Pueraria javanica. Perlakuan jenis tanah memberikan pertumbuhan Pueraria javanica yang sama pada parameter jumlah daun, berat segar tajuk, berat kering tajuk, dan jumlah bintil akar, kecuali pada berat segar akar.

\section{DAFTAR PUSTAKA}

Damanik, M, Hasibuan, Fauzi, Sarifuddin, Hanum. 2010. Kesuburan Tanah dan Pemupukan. USU Press. Medan.

Gardner, F.P, R.B. Pearce dan R.I. Mitchell. 1991. Fisiologi tanaman budidaya. UI press. Jakarta.

Hardjowigeno, S. dan M. L. Rayes. 2005. Tanah Sawah. Karakteristik, Kondisi, dan Permasalah Tanah di Indonesia. Cetakan I. Bayu Media Publishing. Malang. Jatim. Indonesia.

Harsanto W.A., I.Y. Harahap, Y. Pangaribuan \& T.C. Hidayat. 2012. Penggunaan berbagai Jenis Legume Cover Crop (LCC) pada Pertanaman Kelapa Sawit (Elaeis guineensis Jacq). di Lahan Gambut.Medan:Warta Pusat Penelitian kelapa Sawit 17 (2): 45-50.

Hartono, J.M.V, 1990. Teknologi bahan bangunan bata dan genteng. Balai Penelitian Keramik. UGM.

Ige DV, OO Akinremi and DN Flaten. 2005. Direct and indirect effects of soil properties on phosphorus retention capacity. Soil Science Society of America Journal 71, 95-100

Kurniaty, R., Sofwan, B. dan Enny, W. 2013. Penggunaan Rhizobium sp. dan Mikoriza Dalam Pertumbuhan Bibit Kaliandra Umur 5 Bulan. Jurnal Perbenihan Tanaman Hutan. 2(1): 71-81.

Mulyadi, A. 2012. Pengaruh pemberian legin, pupuk NPK (15:15:15) dan urea pada tanah gambut terhadap kandungan N, P total pucuk dan bintil akar kedelai [Glycine max (L.) Merr.]. Kaunia 8:21-29.Pahan, lyung. 2012. Panduan Lengkap Kelapa Sawit. Manajemen Agribisnis dari Hulu Hinnga Hilir. Penebar Swadaya, Bogor.

Purba, A. 2005 Tanaman Penutup Tanah Dan Gulma Pada Kelapa Sawit.Pusat Penelitian Kelapa Sawit (PPKS Medan) 